This chapter provides a theory of informal and incidental learning and updates this theory based on recent research.

\title{
Informal and Incidental Learning
}

\author{
Victoria J. Marsick, Karen E. Watkins
}

Informal and incidental learning is at the heart of adult education because of its learner-centered focus and the lessons that can be learned from life experience. But learning from experience is so broad that everything from Outward Bound activities to structured computer simulations is included in the definition. In this chapter we define informal and incidental learning and look at questions that arise when adult educators use this type of learning in research and practice.

\section{What Informal and Incidental Learning Look Like}

We define informal and incidental learning by their contrast with formal learning:

\begin{abstract}
Formal learning is typically institutionally sponsored, classroom-based, and highly structured. Informal learning, a category that includes incidental learning, may occur in institutions, but it is not typically classroom-based or highly structured, and control of learning rests primarily in the hands of the learner. Incidental learning is defined as a byproduct of some other activity, such as task accomplishment, interpersonal interaction, sensing the organizational culture, trial-and-error experimentation, or even formal learning. Informal learning can be deliberately encouraged by an organization or it can take place despite an environment not highly conducive to learning. Incidental learning, on the other hand, almost always takes place although people are not always conscious of it [Marsick and Watkins, 1990, p. 12].
\end{abstract}

Informal learning is usually intentional but not highly structured. Examples include self-directed learning, networking, coaching, mentoring, and 
performance planning that includes opportunities to review learning needs. When people learn incidentally, their learning may be taken for granted, tacit, or unconscious. However, a passing insight can then be probed and intentionally explored. Examples are the hidden agenda of an organization's culture or a teacher's class, learning from mistakes, or the unsystematic process of trial and error.

The origins of our theory of informal and incidental learning have been reviewed by us (Marsick and Watkins, 1990) and by Garrick (1998). In these reviews, informal and incidental learning have been linked to related concepts, such as learning "en passant" (Reischmann, 1986), the distinctions several others have made between formal, informal, and nonformal learning (Coombs and Ahmed, 1974; Mocker and Spear, 1982; Jarvis, 1987), social modeling (Bandura, 1986), experiential learning (Boud, Cohen, and Walker, 1993; Kolb, 1984), self-directed learning (Candy, 1991; Knowles, 1950), action learning as a variant of experiential learning (Revans, 1982), action science (Argyris and Schön, 1974, 1978) and reflection in action (Schön, 1983), critical reflection and transformative learning (Mezirow, 1991), tacit knowing (Nonaka and Takeuchi, 1995; Polanyi, 1967), situated cognition (Scribner, 1986; Lave and Wenger, 1991), and communities of practice (Wenger, 1998). These concepts are related to informal and incidental learning, but they are not synonymous with the terms in the way that we use them here.

\section{What We've Learned from Research}

Mary Callahan (1999) identified almost 150 studies when doing her research on this topic. A review of this research makes it immediately clear that informal and incidental learning are relevant to practice in many cultures and contexts: the private and public sectors, hospitals and health care, colleges and universities, schools, professional associations, museums, religions, families, and communities.

Some specific studies illustrate how such knowledge enhances our learning. Dana Diesel and Elizabeth Colbert, doctoral students at Teachers College, Columbia University, are conducting a joint study in an experimental elementary school in North Carolina. Colbert is one of the school's leaders, but all administrators also teach and all teachers also participate in governance. Colbert and Diesel are studying how teachers learn informally through reflection and action and ways in which their collaboration is nurtured in the culture. In many schools, professional development for teachers is often limited to occasional, brief in-service sessions. The findings from this study can be used to design policies, practices, and a culture that supports ongoing learning that is integrated with daily work routines within the school.

Callahan (1999) studied incidental learning in a publicly funded small-business incubator. Business incubators support new entrepre- 
neurial ventures by providing technical assistance, resources, and services. The incubator provided opportunities and a culture for informal observing and talking with others, particularly those who used the incubator's free office space with new ventures housed in the same space once occupied by now successful startups. Callahan's interviewees referred to one kind of incidental learning as the "karma in the walls and halls." Observing other start-up companies provided participants with "a virtual blueprint" to guide early entrepreneurial steps. "Bridging" learning helped people with different professional backgrounds (in this instance, technical entrepreneurs and venture capitalists) to understand one another and work more effectively together. By providing opportunities for interaction and sharing, adult educators built on the natural enthusiasm for learning of these technically-oriented entrepreneurs and moved them from learning about their technical innovations to learning about managing a business.

Maria Cseh's (1998) study found that the learning of the owner-managers of small, successful, private companies in Romania was stimulated mostly by the context, particularly the ambiguity, of a quasi-market economy. One of the major lessons learned by these owner-managers was that although there were many changes after the collapse of the Communist regime, little changed in the way human relationships in business were conducted. Thus, those managers who did not have managerial experience in the previous regime had to learn how to work with the government and state-owned companies, while those who had previous experience had difficulty unlearning previous politically-driven practices that only worked half of the time. Cseh's study poses questions for research and practice around the nature and facilitation of "unlearning." As illustrated by the Eastern European managers in this study, freeing oneself from existing mental models that constrain the way work is done is not easy.

Studies by Carter (1995) and Menard (1993) illustrate that informal and incidental learning are often the result of a significant unplanned or unexpected event. Carter studied stroke survivors whose newsletter title speaks to their surprise trigger to learning: "A Stroke of Luck." Her study found that stroke survivors more often than not had to figure out on their own a solution to the problems they encountered, despite health care systems that intended to be supportive. Menard's study looked at the informal and incidental learning of nurses in Vietnam. Numerous critical incidents identified the satisfaction the nurses found in their own ingenuity in inventing tools or techniques to accommodate for the lack of critical supplies in MASH units.

Finally, a study by Watkins and Cervero (2000) sought to determine whether two different organizational settings of CPA practice produced substantially different or equivalent learning opportunities for a practicing CPA. The study was conducted to provide expert testimony for a lawsuit. The CPA worked for approximately two-and-a-half years in a registered CPA 
firm, at which point he became an employee of a financial services firm that was not a registered CPA firm. The questions raised in the lawsuit had to do with the time needed in either environment for professional certification (labeled "experience credit" by CPAs-or time-learning-by-doing accounting). Watkins and Cervero constructed a survey of thirty-one possible formal, informal, and incidental learning opportunities. For example, they asked whether the CPA had opportunities to learn from instructional videos, from being assigned increasingly difficult accounting projects, and from critiquing sessions with supervisors. The new CPA participated in twenty-one out of the twenty-five learning opportunities available at both organizations. Learning was intricately woven into the fabric of work in both organizations. Watkins and Cervero concluded that there was a strong culture and support for learning at both organizations, and no substantial difference between the firms in the formal, informal, and incidental learning opportunities available.

Adult educators and organizations can learn from the structures and strategies supported by professional service firms and from the research presented briefly here. The organizational context produces different work assignments, which, in turn, lead to different opportunities and priorities for learning. The organization can provide different incentives for learning, such as tuition reimbursement, and resources, such as a library of reference material, subscriptions to professional journals, video courses, or computer-based courses. In particular, the organization can encourage peers to work and learn collaboratively (Marsick and Watkins, 1999; Watkins and Marsick, 1993, 1996).

Informal and incidental learning take place wherever people have the need, motivation, and opportunity for learning. After a review of several studies done on informal learning in the workplace, Marsick and Volpe (1999) concluded that informal learning can be characterized as follows:

- It is integrated with daily routines.

- It is triggered by an internal or external jolt.

- It is not highly conscious.

- It is haphazard and influenced by chance.

- It is an inductive process of reflection and action.

- It is linked to learning of others [p. 5].

\section{Model for Enhancing Informal and Incidental Learning}

Figure 3.1 depicts a model for enhancing informal and incidental learning that Marsick and Watkins developed initially in 1990 and have subsequently modified, most recently in collaboration with Cseh (Cseh, Watkins, and Marsick, 1999). The model is rooted in the thinking of John Dewey (1938), Argyris and Schön $(1974,1978)$, and Mezirow (1991). 
Figure 3.1. Marsick and Watkins's Informal and Incidental Learning Model as Adapted with Cseh

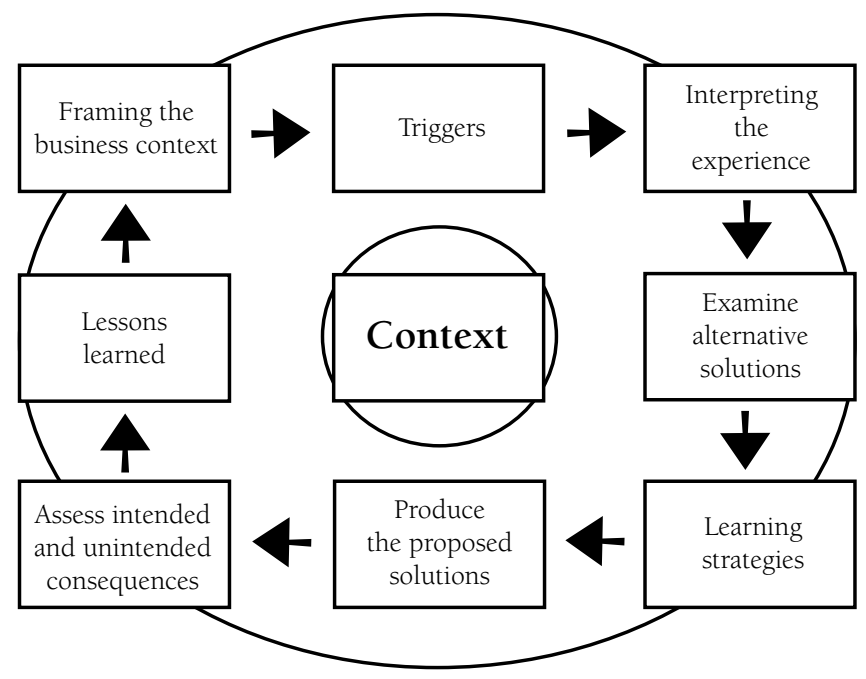

The circle in the center represents our belief that learning grows out of everyday encounters while working and living in a given context. A new life experience may offer a challenge, a problem to be resolved, or a vision of a future state. The outer circle represents the context within which the experience occurs, the personal, social, business, and cultural context for learning that plays a key role in influencing the way in which people interpret the situation, their choices, the actions they take, and the learning that is effected.

The model depicts a progression of meaning making that, in practice, is often more of an ebb and flow as people begin to make sense of a situation. With each new insight, they may have to go back and question earlier understandings. The model is arranged in a circle, but the steps are neither linear nor necessarily sequential.

In this newest version of our model, we have integrated the incidental learning process since it is clear to us that it is always occurring, with or without our conscious awareness. For example, we note that learning begins with some kind of a trigger, that is, an internal or external stimulus that signals dissatisfaction with current ways of thinking or being. This trigger or experience encountered is often a surprise, such as the sudden departure of a leader. But in the model, preceding this is our worldview, our way of seeing things that frames what we pay attention to, how we will see this new trigger. This frame is a pivotal point in the model since it can also be influenced by the lessons learned at the end of a learning cycle. Our model shows that people diagnose or frame a new experience that they encounter. They assess what is problematic or challenging about it. They compare the 
new situation with prior experience, identify similarities or differences, and use their interpretation to make sense of the new challenge.

People refine their diagnosis by interpreting the context. They attend to the different factors in the context that influence their interpretation. The context might simply involve one other person, say a family member or coworker, and a relatively routine interaction. Or it might be highly complex, with multiple actors and many political, social, or cultural norms that have never before been addressed. Interpreting the context is a greater challenge when social norms and expectations are in a state of flux, or when the person himself or herself is learning something new. Also, people do not have the same level of skill or awareness around contextual factors that influence an interpretation, and they are subject to blind spots that can, at times, be intensified when emotional factors come into play.

Interpretation of the context leads to choices about alternative actions. These choices are guided by recollections of past solutions and by a search for other potential models for action. Success in implementation depends on drawing on capabilities that are adequate to the task. If the solution calls for new skills, the person needs to acquire these. Many contextual factors influence the ability to learn well enough to successfully implement the desired solution. These include, but may not be limited to, the availability of appropriate resources (time, money, people from whom to learn, available knowledge about an unknown or ambiguous phenomena), willingness and motivation to learn, and the emotional capacity to take on new capabilities in the middle of what could be a stressful challenge.

Once an action is taken (a solution produced), a person can assess the outcomes and decide whether or not they match his or her goals, the intended results. It is relatively easy to assess intended consequences if a person takes the time up front to make his or her goals clear and explicit. This step of judging consequences then enables a person to draw lessons learned and to use these lessons in planning future actions. These concluding thoughts are the new understandings or frame that a person would bring when encountering a new situation, which brings us back full circle to the beginning of the cycle.

\section{Implications for Practice: Enhancing Informal and Incidental Learning}

Informal and incidental learning generally take place without much external facilitation or structure. In our work, we emphasize three conditions to enhance this kind of learning: critical reflection to surface tacit knowledge and beliefs, stimulation of proactivity on the part of the learner to actively identify options and to learn new skills to implement those options or solutions, and creativity to encourage a wider range of options. 
Individuals who want to enhance this learning can increase their own awareness of the learning opportunities posed by life experiences and gain insight into their learning preferences. Adult educators might provide a structure within which to take advantage of learning opportunities and gain insight into oneself as learner. Honey and Mumford (1989), for example, provide guidelines for self-analysis of learning styles and for action planning around improved capability. Many organizations use learningstyle instruments in career-planning workshops to encourage employees to become more self-directed in planning their careers and development. People learn how they learn, examine multiple ways to learn, and look for ways to more effectively plan their future learning to play to their learning preferences.

Adult educators can also help learners identify conditions in the sociocultural context that help them learn more effectively or that stand in the way of learning. Once these factors are identified, educators can help learners change or deal with them. For example, a number of governments no longer provide indefinite welfare assistance to poor people and instead require them to work. Programs that prepare welfare recipients for getting and keeping work may not question the role that society has played in causing the conditions that create poverty or the discrimination that some people may experience due to their gender, race, or class. Poor welfare women may learn incidentally that they are to blame for many of their problems. When these women learn informally about work opportunities, they may seek socially sanctioned work paths that actually reinforce a cycle of poverty. Adult educators in these programs could help women examine the validity of socially constructed viewpoints and thereby help them to be more proactive.

Because informal and incidental learning are unstructured, it is easy to become trapped by blind spots about one's own needs, assumptions, and values that influence the way people frame a situation, and by misperceptions about one's own responsibility when errors occur. When people learn in families, groups, workplaces, or other social settings, their interpretation of a situation and consequent actions are highly influenced by social and cultural norms of others. Yet, people often do not deeply question their own or others' views. Power dynamics may distort the way in which they understand events. These issues make it imperative that we teach adult learners strategies to make this kind of learning both more visible and more rigorous.

\section{Conclusion}

We are pleased with the progress scholars have made in deepening our understanding of the nature of informal and incidental learning in the past ten years. It seems clear that these are the most pervasive forms of adult learning and that we can indeed enhance this kind of learning with educational intervention. 
The studies noted in this chapter richly describe the processes and strategies learners use when learning informally and incidentally.

Yet there remain a number of interesting questions. First, without intervention or critical reflection, it is equally possible to hold incorrect as well as correct assumptions. More studies such as that currently being conducted by Wilson (2000) of hotel managers' defensive reasoning may help us learn more about the tacit processes by which individuals embed error. In fact, we suggest that with an incorrect frame on a problem, every step in the cycle is compromised so that we are solving the wrong problem and drawing incorrect inferences from the results we obtain.

We need to learn more about the interface between learning at the individual, team, and organizational levels. We have defined learning at the individual level as the way in which people make meaning and acquire knowledge and skill; learning at the team level as the mutual construction of new knowledge including the capacity for concerted, collaborative action; and learning at the organizational level as that which is embedded in systems, policies, procedures, work processes and information systems, organizational mental models, schema, and knowledge embedded in products and services. What are the nuances, the differences between and among these levels? To what extent are they accurate? What happens at the intersection of individual and team, of team and organization?

Finally, technology is changing the face of organizations and having an impact on the nature of informal and incidental learning. In fact, given the distributed, asynchronous nature of technology-facilitated interactions, more may be learned incidentally by learners reading between the lines. As we work to bring adult education to the Web, studies exploring how people learn in these settings are needed.

Informal and incidental learning can be enhanced with facilitation or increased awareness by the learner. Formal adult learning may also be enhanced if adult educators heed the lessons learned informally and incidentally. While much is known about these pervasive forms of adult learning, much remains to be learned.

\section{References}

Argyris, C., and Schön, D. Theory in Practice: Increasing Professional Effectiveness. San Francisco: Jossey-Bass, 1974.

Argyris, C., and Schön, D. Organizational Learning: A Theory of Action Perspective. San Francisco: Jossey-Bass, 1978.

Bandura, A. Social Foundations of Thought and Action: A Social Cognitive Theory. Englewood Cliffs, N.J.: Prentice-Hall, 1986.

Boud, D., Cohen, R., and Walker, D. (eds.) Using Experience for Learning. Buckingham, England: The Society for Research into Higher Education and Open University Press, 1993.

Callahan, M.H.W. Case Study of an Advanced Technology Business Incubator as a Learning Environment. Unpublished doctoral dissertation, The University of Georgia, Athens, 1999.

Candy, P. C. Self Direction for Lifelong Learning: A Comprehensive Guide to Theory and Practice. San Francisco: Jossey-Bass, 1991. 
Carter, G. Stroke Survivors: Finding Their Way Through Informal and Incidental Learning. Unpublished doctoral dissertation, University of Texas, Austin, 1995.

Coombs, P., and Ahmed, M. Attacking Rural Poverty: How Nonformal Education Can Help. Baltimore: Johns Hopkins University Press, 1974.

Cseh, M. Managerial Learning in the Transition to a Free Market Economy in Romanian Private Companies. Unpublished doctoral dissertation, The University of Georgia, Athens, 1998.

Cseh, M., Watkins, K. E., and Marsick, V. J. "Re-conceptualizing Marsick and Watkins' Model of Informal and Incidental Learning in the Workplace." In K. P. Kuchinke (ed.), Proceedings, Academy of Human Resource Development Conference, Volume I (pp. 349-356), Baton Rouge, LA: Academy of Human Resource Development, 1999.

Dewey, J. Experience and Education. New York: Collier Books, 1938.

Garrick, J. Informal Learning in the Workplace: Unmasking Human Resource Development. London: Routledge, 1998.

Honey, P., and Mumford, A. Capitalizing on Your Learning Style. (2nd ed.) King of Prussia, PA: Organization Design and Development, 1989.

Jarvis, P. Adult Learning in the Social Context. London: Croom-Helm, 1987.

Knowles, M. Informal Adult Education. New York: Association Press, 1950.

Kolb, D. A. Experiential Learning. Englewood Cliffs, NJ: Prentice-Hall, 1984.

Lave, J., and Wenger, E. Situated Learning-Legitimate Peripheral Participation. Cambridge: Cambridge University Press, 1991.

Marsick, V. J., and Volpe, M. "The Nature of and Need for Informal Learning." In V. J. Marsick and M. Volpe (eds.), Informal Learning on the Job, Advances in Developing Human Resources, No. 3. San Francisco: Berrett Koehler, 1999.

Marsick, V. J., and Watkins, K. Informal and Incidental Learning in the Workplace. London and New York: Routledge, 1990.

Marsick, V. J., and Watkins, K. Facilitating Learning Organizations: Making Learning Count. Aldershot, England: Gower Publishers, 1999.

Menard, S.A.W. Critical Learning Incidents of Female Army Nurse Vietnam Veterans and Their Perceptions of Organizational Culture in a Combat Area. Unpublished doctoral dissertation, Abstracts International 55-01A (4651) (University Microfilm No. AAI9413556), University of Texas, Austin, 1993.

Mezirow, J. D. Transformative Dimensions of Adult Learning. San Francisco: Jossey-Bass, 1991.

Mocker, D. W., and Spear, G. E. Lifelong Learning: Formal, Non-Formal, Informal and Self-Directed. Columbus, OH: ERIC Clearinghouse on Adult, Career and Vocational Education, 1982.

Nonaka, I., and Takeuchi, H. The Knowledge Creating Company. New York: Oxford, 1995.

Polanyi, M. The Tacit Dimension. New York: Doubleday, 1967.

Reischmann, J. "Learning 'En Passant': The Forgotten Dimension." Paper presented at the American Association of Adult and Continuing Education Conference, 1986.

Revans, R. W. The Origins and Growth of Action Learning. Bickly, Kent: Chartwell-Bratt, and Lund, Sweden: Studenlitteratur, 1982.

Schön, D. A. The Reflective Practitioner. New York: Basic Books, 1983.

Scribner, S. "Thinking in Action: Some Characteristics of Practical Thought." In R. J. Sternberg and R. K. Wagner (eds.), Practical Intelligence: Nature and Origins of Competence in the Everyday World. Cambridge, England: Cambridge University Press, 1986.

Watkins, K. E., and Cervero, R. "Organizations as Contexts for Learning: Differentiating Opportunities and Experiences of a Certified Public Accountant." Journal of Workplace Learning, 2000, 12(5), 187-194.

Watkins, K., and Marsick, V. J. Sculpting the Learning Organization. San Francisco: Jossey-Bass, 1993. 
Watkins, K., and Marsick, V. J. In Action: Creating the Learning Organization. Arlington: ASTD Press, 1996.

Wenger, E. Communities of Practice. Cambridge: Cambridge University Press, 1998.

Wilson, J. Defensive Reasoning of Hotel Managers. Unpublished doctoral dissertation, The University of Georgia, Athens, 2000.

VICTORIA J. MARSICK is professor of adult education at Teacher's College, Columbia University. She is also the director of the Huber Institute for Transformative Learning at Columbia.

KAREN E. WATKINS is professor of adult education and interim director of the School of Leadership and Lifelong Learning at The University of Georgia. 